\title{
Universal and dialect-specific pathways of acquisition: Caregivers, children, and $\mathbf{t} / \mathbf{d}$ deletion
}

\author{
JENNIFER SMITH \\ University of Glasgow \\ Mercedes Durham \\ University of Aberdeen \\ Liane Fortune \\ University of York
}

\section{A B S T R A C T}

T/d deletion is one of the most widely studied variables in sociolinguistic research, and findings demonstrate universal morphological and phonological constraints across a range of dialects. Research into the acquisition of this variable suggests that articulatory constraints are learned first, followed by grammatical, and finally stylistic and social constraints. Dialect-specific constraints are also found, implicating the caregiver in the process of acquisition. In this article, we contribute to this research on the acquisition of $t / d$ through the examination of the speech of preschool children in interaction with their primary caregivers in a community in Scotland. Our results mirror previous results on how and when particular constraints are acquired, providing further evidence for universal order of acquisition of this form. We also demonstrate dialect-specific constraints on use that can be mapped directly to caregiver speech. This provides additional evidence on how variable forms are transmitted from parent to child in these early stages.

One of the first linguistic variables to be studied in sociolinguistic research was coronal stop deletion, or more commonly t/d deletion, in word-final consonant clusters (Labov \& Cohen, 1967) as in (1).

\section{(1) Lift your han Ø! Lift your hand!}

In the intervening years since it was first identified, $\mathrm{t} / \mathrm{d}$ deletion has become a "showcase variable" (Patrick, 1999:171), studied in a wide range of sociolinguistic settings (e.g., Bayley, 1994; Fasold, 1972; Guy, 1980; Guy \&

We gratefully acknowledge the support of the Economic and Social Research Council award no. RES-000-22-0477. We thank Julie Roberts, James Walker, and two anonymous reviewers for helpful feedback on earlier versions of this manuscript. Thanks also to the caregivers and children in Buckie - this research would not be possible without them. 
Boberg, 1997; Labov, 1975; Neu, 1980; Reynolds, 1994; Santa Ana, 1992, 1996; Tagliamonte \& Temple, 2005; Wolfram, 1969; Wolfram \& Christian, 1976). Results from these studies indicate that $\mathrm{t} / \mathrm{d}$ deletion is "omnipresent in a range of English speakers" (Guy, 1980:34). In fact, so prevalent is this variable that it has been described as "a primitive of vernacular dialects in the sense that [it] recurs ubiquitously all over the world" (Chambers, 2003:265). Moreover, it is "very stable and uniform with regard to its major constraints" (Guy, 1980:34), namely following phonological segment and morphological class. This claim to universality of constraints, regardless of ethnicity, class, age, or indeed any other sociolinguistic measure, finds widespread empirical support across a range of dialects (e.g., Guy, 1980), although dialect-specific influences are also found (e.g., Patrick, 1999; Tagliamonte \& Temple, 2005).

Given the uniformity of results for adult data, researchers have turned to the intriguing question of how this showcase variable might emerge at the source, that is, in the speech of very young children acquiring this feature, as in (2):

(2) a. It's not time for breakfas $\emptyset$ yet. It's not time for breakfast yet. (Annie, 3;3 [years;months])

b. I'm finished. Are you finishe Ø mam? (Lucy, 3;4)

c. Mammy I droppe Ø the pieces, I dropped it. (Isabel, 3;0)

Labov (1989:96) observed that "if we were to assume that this aspect of language learning were controlled by innate, universal principles, then we would expect to find the following order of acquisition": (a) articulatory constraints, (b) grammatical constraints, and (c) stylistic and social constraints. This finds empirical support in Roberts's $(1995,1997)$ large-scale analysis of $\mathrm{t} / \mathrm{d}$ deletion in the speech of preschool children in North America. Children as young as 3 years old had largely mastered the phonological constraints on $\mathrm{t} / \mathrm{d}$ deletion, only partly acquired the grammatical constraints, but had not acquired the social constraints on use. Further, dialect-specific constraints attested in the speech of the caregivers are also in evidence in the children's speech, leading Roberts to suggest that young children are "learning rules grounded in a socially transmitted dialect rather than applying a universal constraint" (Roberts, 1997:369).

The patterns of use in adult data are replicated across a range of dialects. Are the patterns of acquisition of these forms in young children replicated elsewhere? How exactly is caregiver input implicated in the interplay between universal and dialectspecific in this process? In this study, we seek to contribute to these questions through the analysis of preschool children and their primary caregivers involved in everyday interaction. The study both complements and extends Roberts's work. Her study examined a group of children from a large urban area, Philadelphia; we analyze speech data from a small, rural community in northern Scotland. Roberts's data included caregiver talk in interaction with another adult as a point of comparison with the children's speech; we examine caregivers and their children in interaction to explore further the interplay between input and output. Through this analysis, we hope to provide further insights into how 
and when this primitive of vernacular dialects is transmitted from parent to child in these first stages of language acquisition.

PREVIOUS RESEARCH ON T/D

Specific constraints on $\mathrm{t} / \mathrm{d}$ have been shown to hold across a number of varieties of English. We concentrate here on the main internal constraints reported: preceding and following phonological segment, morphological category, in addition to a number of social constraints on use.

\section{Following phonological segment}

Following phonological segment is consistently shown to be the strongest constraint across a range of dialects and a generalized hierarchy of use is common to most varieties: following obstruents, as in (3), promote deletion, followed by liquids (4), then glides (5), and vowels (6) (e.g., Guy, 1980; Neu, 1980; Roberts, 1997; Tagliamonte \& Temple, 2005). Guy (1980:7) accounted for this hierarchy in terms of distinctive features: if consonants [ + cons - voc] favor deletion, then their binary opposites-vowel [-cons, + voc]-disfavor deletion. Glides [-cons, -voc] and liquids [+cons, +vowel] have one favoring and one disfavoring feature and are thus intermediate between consonants and vowels. Pause, as in (7), on the other hand, is "physically, acoustically and functionally outside [this] system" (Guy, 1980:27), "hence [it has] no obvious position in the effect hierarchy" (Guy, 1980:8). Thus it may not be surprising that dialect-specific orderings on pause are found (e.g., Guy, 1980; Labov, 1975; Roberts, 1997; Tagliamonte \& Temple, 2005). ${ }^{1}$

(3) Oh a present for me now. (Stephen, 3;2)

(4) Fin $\varnothing$ Lala's head first. (caregiver)

(5) Wild wind outside. (caregiver)

(6) You crashed it again. (Lyle, 3;3)

(7) It's all finished. (Max, 2;11)

\section{Preceding phonological segment}

Preceding phonological segment has also been found to have an effect and is linked to sonority of the preceding segment (Bayley, 1994:384; Fasold, 1972; Guy, 1980; Guy \& Boberg, 1997; Labov, 1989:90; Santa Ana, 1996:68). Less sonorous segments favor deletion, and more sonorous disfavor it. Various classifications have been employed: obstruents versus sonorants (Labov \& Cohen, 1967); fricatives, stops, and sonorants (Wolfram, 1969); distinctive features- $[+$ cor, - son, - cont], [- son, - cont] —(Fasold, 1972; Guy \& Boberg, 1997); sibilant, fricative, nasal, stop, and lateral (Guy, 1980). Although the details between dialects may differ, Labov (1989) suggested the following broad hierarchy of use: $/ \mathrm{s} />$ stops $>$ nasals $>$ other fricatives $>$ liquids, as in (8) to (12). 
(8) I missed it. (Kieran, 3;6)

(9) Mam's droppe Ø you off. (Ellie, 3;5)

(10) What about your frien $\varnothing$ the octopus? (caregiver)

(11) Now, what have we got lefø with now? (caregiver)

(12) No hold on, it goes in there. (caregiver)

\section{Morphological category}

In addition to these phonological constraints, grammatical category is also found to exert a statistically significant effect on consonant cluster deletion: monomorphemes, as in (13) are more likely to be deleted than past tense morphemes (14). The lower rates of deletion in regular past tense contexts are said to arise due to a "tendency for semantically relevant information to be retained in surface structure" (Kiparsky, 1982:87). ${ }^{2}$ Semiweak verbs (15) are situated somewhere in between (e.g., Fasold, 1972; Guy, 1980; Neu, 1980; Santa Ana, 1992; Wolfram \& Christian, 1976), although this is subject to agegrading (see discussion of the acquisition of $\mathrm{t} / \mathrm{d}$ below). ${ }^{3}$

(13) You'll have to hold mammie's han $\varnothing$. (caregiver)

(14) No, I asked first. (Kerry, 3;2)

(15) Mam I found it. (Luke, 3;5)

\section{Social constraints}

In general, this variable "elicit[s] only moderate style shifting and subjective reactions" across a number of dialects (Labov, 2001:196), although Wolfram (1969) found higher rates of deletion in casual styles compared with reading aloud (see also Fasold, 1972; Guy, 1980). Gender, social class, and educational level show mild stratification (e.g., Neu, 1980; Wolfram, 1969), but ethnicity and age are found to be the strongest constraint on this variable (Santa Ana, 1992). See Santa Ana (1992) for a very detailed literature review on these constraints.

Extrapolating from these studies, the main constraints on adult use of $t / d$ deletion can be summarized as follows:

Following phonological segment:

Preceding phonological segment:

Morphological class:

Gender:

Style:

Class: obstruents $>$ liquids $>$ glides $>$ vowels/pause

/s/ $>$ stops $>$ nasals $>$ other

fricatives $>$ liquids

monomorphemes $>$ semiweak $>$

regular past tense

male $>$ female

informal $>$ formal

working class $>$ middle class 
Ethnicity:

African American $\quad$ Vernacular
English $>$ anglo American

ACQUISITION

\section{The acquisition of consonant clusters}

Consonant cluster simplification/deletion is a well-documented feature of the acquisition of first language phonology, described as "the most common and longest lasting stage" (Shriberg \& Kwiatkowski, 1980:138). In this research, the concentration is largely on nontarget forms, such as, /pardər/ for /spardər/ and $/ \mathrm{kæk} /$ for $/ \mathrm{kræk} /$, and the stages at which the "correct" forms are acquired. McLeod, van Doorm, and Reed (2001a), for example, found in their sample of conversational data from children aged $2 ; 0$ to $3 ; 4$ that only $30 \%$ of the utterances were target clusters. By the age of 4;0, nearly $90 \%$ of consonant clusters are targetlike (e.g., Waring, Fisher, \& Atkin, 2001). Word-final consonant clusters appear earlier in inventories than word-initial clusters do (McLeod et al., 2001a): /-nt/, /-nd/, /-st/ are noted to appear around 3;0 (e.g., McLeod et al., 2001b; Stoel-Gammon, 1987) but laterals and obstruents plus /t/ or /d/ may appear around $4 ; 0$.

In addition to articulatory considerations, grammatical development in first language acquisition also needs to be taken into account. Regular past tense or past participle -ed verbs first appear unmarked, that is, as stems in young children's speech (e.g., Radford, 1992), and in fact, regular past tense marking comes rather late in morphological development, around 41-46 months (Brown, 1973). Thus although $\mathrm{t} / \mathrm{d}$ deletion may be present in consonant clusters, this may be part of a more generalized process of first language acquisition and be better characterized as t/d absence.

Despite the large body of work on acquisition of consonant clusters, Kirk and Demuth (2005:710) reported that there has been relatively little discussion "regarding children's productions relative to the standard adult pronunciation." In studies of the acquisition of $t / d$, in contrast, researchers have taken as the starting point patterns of variable use in the adult data. We now turn to a review of these studies.

\section{The acquisition of $t / d$}

Labov (1989:85) was the first to focus on the acquisition of $t / d$ in a small-scale study of a middle class family in King of Prussia in the suburbs of Philadelphia, with the aim of establishing in which order constraints would be acquired. However, the limited nature of the study makes it difficult to draw any firm conclusions. This is particularly true for the two children under 4 years old, who share only a handful of tokens of $\mathrm{t} / \mathrm{d}$ between them. He does tentatively conclude however that the "active period" for acquisition of $\mathrm{t} / \mathrm{d}$ "lies at or above 4 years" (Labov, 1989:96). 
Guy and Boyd (1990) concentrated on t/d deletion in semiweak verbs in American English speakers aged 4-65. The categorical deletion in semiweak verbs with the youngest children led them to conclude that "children simply do not have a final apical stop in the underlying forms of these words" (Guy \& Boyd, 1990:11). Where they do occur, they are described as "sporadic borrowings from their adult models" (Guy \& Boyd, 1990:11). Only later do they show a tendency to treat these derivational affixes in the same way as past tense inflections. From these data, it is clear that morphological class, and in particular, semiweak verbs, is subject to age-grading. However, the sparse data for younger speakers forces them to group all children below 10 years old together, making it difficult to pinpoint more closely the active period for acquisition of this constraint.

Compelled by the lack of data on younger subjects, Roberts $(1995,1997)$ embarked on the first large-scale study of t/d deletion, focusing on 16 working class urban South Philadelphian children $(3 ; 2-4 ; 11)$ and their caregivers. The children were recorded in "play-interview" sessions at their nursery school, and 8 of the 16 caregivers were recorded in their homes. The results showed that "children as young as three had, for the most part, mastered the phonological constraints on (-t, d) deletion" (Roberts, 1997:351), as they replicated the Philadelphia adult pattern with respect to following phonological segment: obstruent $>$ liquid/glide $>$ vowel $>$ pause. The dialect-specific patterning for pause $>$ vowel supports Guy's (1980:28) statement that pause is arbitrarily defined in any given dialect and must be learned by children. They had also partly acquired the hierarchies of use for grammatical category: monomorphemes were shown to have higher rates of deletion than regular past tense forms, just as in the caregiver data. However, in contrast to the caregiver data, semiweak verbs patterned like monomorphemes. The complete absence of t/d in semiweak verbs in Guy and Boyd's (1990) youngest speakers led them to conclude there was no underlying t/d at this stage. Roberts's high but not categorical rates, on the other hand, led her to conclude that $\mathrm{t} / \mathrm{d}$ is present in the underlying form, although the children analyze semiweak verbs as monomorphemes rather than productive past tense markers. She also suggested that these results provide evidence that children do not simply imitate surface forms, but form higher level rules to "fit" their grammar at that particular point of development. In contrast to the acquisition of these internal constraints, these children were "not as successful in acquiring the social constraints" (Roberts, 1997:365): there was no evidence of style-shifting according to addressee or play context. When considering the difference between girls and boys, her results showed that the girls deleted at a significantly higher rate than the boys did, perhaps because "girls have not yet responded linguistically" (Roberts, 1997:368) to the gender differences that arise in later life. Finally, dividing the children into groups of 3- and 4-year-olds did not yield statistically significant differences between the two age groups in terms of frequency of use. Using mean length of utterance as a measure of maturity also did not yield statistically significant results. 
In sum, the results for adult data suggest very similar constraints on use across a wide range of dialects on the use of $t / d$ deletion. The results for acquisition of these forms suggest that both universal and dialect-specific constraints are learned from an early age and that a particular pathway of development is followed: articulatory, grammatical, social.

Roberts's research provides an excellent window into how and when this widespread variable is acquired. In this study, we wish to take the research one step further: not only do we analyze a different variety but our data examines caregivers and children in interaction to investigate more directly the effects of caregiver input. Although the constraints on $\mathrm{t} / \mathrm{d}$ deletion are replicated across a wide range of dialects in adult talk, caregiver speech may differ. It is said to be a clearer, simpler form of talk (e.g., Snow, 1995) and may contain "fewer less carefully articulated ... segments" (Malsheen, 1980:184), ${ }^{4}$ which is said to "assist the child's analysis of linguistic materials" (Garnica, 1977:81). In this case, we might expect more carefully articulated consonant clusters, that is, less deletion in caregiver speech. This in turn may affect the patterns of use, where the children are presented with a different model to that which is widely attested. Our data will allow us to directly test this hypothesis. We now turn to the data at hand.

DATA AND METHOD

\section{The community}

The data come from a small fishing town, Buckie (population approximately 8,000 ), which is situated on the northeast coast of Scotland. The speech community forms a linguistically homogeneous group (e.g., Smith, 2000a, 2000b, 2001), which provides a highly controlled environment for tracking the emergence of structured variation in child language.

\section{The sample}

The caregiver/child corpus contains 11 dyads aged between 2;11 and 3;11 (see detail in Smith, Durham, \& Fortune, 2007) as shown in Table 1. All caregivers are mothers of the children. To control the sample as much as possible, a number of stipulations were made: both parents born and raised in the community, the mother the main caregiver, no child in formal nursery education.

\section{Data collection}

The collection of data from young children poses a number of problems, particularly with respect to obtaining adequate amounts for quantitative analysis (e.g., Roberts, 2002). For this study, an innovative methodology was employed: the caregivers were provided with lightweight minidisk recorders (Sony MZ-R700) and lapel microphones (Sony ECM-T145) and requested to undertake a series of recorded sessions in interaction with their child. These 
recordings amounted to 10 hours for each pair, 110 hours in total. Although there are obvious disadvantages in terms of quality of sound in some cases, this data collection technique has proven to be extremely successful in eliciting large amounts of highly vernacular, interactional speech (see detail in Smith et al., 2007).

The minidisk recordings were digitized using Macromedia Soundedit 16, and 5 hours of each caregiver/child dyad was fully transcribed using the Code for Human Analysis of Transcription format (MacWhinney, 1991). The transcription was orthographic in the first instance, although a number of subsequent analyses of the data provided phonetic/phonological variants as well. The total number of words for these 11 pairs of speakers is approximately 250,000.

\section{Circumscribing the variable context}

The first 100 tokens of word-final consonant clusters ending in underlying / $/$ / or /d/ were extracted for each speaker. However, subsequent exclusions meant that this number was considerably reduced across all speakers. To ensure it was possible to look at morphological class, further tokens of semiweak verbs, the least frequent morphological class in the data, were extracted for most of the speakers.

A number of categories were excluded from the start: neutralization contexts, that is, clusters in homorganic environments, as in (16) (see also Bayley, 1994; Fasold, 1972; Guy, 1980, 1991a; Labov, 1989; Neu, 1980; Roberts, 1997; Tagliamonte \& Temple, 2005; Wolfram, 1969), including interdental fricatives as these are often realized as their corresponding stops (see also Tagliamonte \& Temple, 2005:286).

(16) Remember where we went last time? (caregiver)

Tokens of /t/ with a preceding nasal and a following vowel, where nasal flapping can occur, as in (17) are excluded (see also Roberts, 1997:357; Tagliamonte \& Temple, 2005:286).

(17) Do you want a (wanna) drink of milkie? (caregiver)

Consonant clusters of /rd/ or /rt/ as in (18), were excluded, because /r/ is not reliably consonantal in this dialect (see also Stuart-Smith, 2003).

(18) You dinna fall and hurt yourself. (caregiver)

Particular "high-frequency items about whose underlying representation there is some uncertainty" (Guy, 1991a:4; see also Labov, 1989; Patrick, 1991) are excluded: negative contractions, as in (19), the conjunction and as in (20) and the adverbial just, as in (21).

(19) a. One, two, three, can't even count to three him? (caregiver)

b. I don't know what's that. (caregiver) 
(20) The boat and one more. (Ricky, 2;10)

(21) I was just sitting back. (Annie, 3;3)

Overgeneralizations, for example, falled, broked, leaved, in the children's speech as in (22), were excluded from the analysis (see also Roberts, 1997:355).

(22) He broked your car. (Lyle, 3;3)

Lastly, some Scottish-specific lexical items were also excluded. It is noted in the history of Scots that the final consonant in clusters with /nd/ or /ld/, as in (23) and (24), is often deleted (e.g., Dictionary of the Scots Language, History of Scots to $1700)^{5}$

(23) You put your han $\varnothing$ in (Kieran, 3;6)

(24) Mam can you come and hold him a minute? (Ellie, 3;5)

When we examined more closely lexical items in this category, we found that most varied in line with other lexical items. However, a number, including round, cold, and old, involve a vowel change in the local form: /rı $\mathrm{tnd} /$ becomes /ru:n/, /kold/ becomes / kal/, and /old/ becomes /al/ as in (25). These specific dialect forms were found to have very high rates of deletion $(94 \%$ overall, $n=78$ ) so were excluded from the analysis. Furthermore, the lexical item mind (meaning remember), as in (26), also showed (near) categorical deletion, hence was also excluded.

(25) I love calø food. (caregiver)

(26) I canna $\min \varnothing$ his name. (caregiver)

In Scots, regularized preterite forms telt and selt are used alongside the standard told and sold. Preliminary analysis of these regularized forms $(n=35)$ showed that / $t$ / was categorically present in these cases, thus they too were excluded from further analysis.

Auditory analysis was employed, and in line with most other studies, we divided the data into two broad categories of deletion and nondeletion, although the latter category included a number of different types of phonetic reflex including glottal stops. We now turn to the results.

\section{RESULTS}

\section{Overall distributions}

Table 2 shows the overall distribution of $\mathrm{t} / \mathrm{d}$ deletion across the caregiver and child data. From a total of 1,196 tokens, the caregivers have $29.4 \%$ deletion and the children slightly higher rates at $34.5 \%$. The difference between caregivers and children is not statistically significant $(p>0.05$, chi-square $=3.0108)$. The 
TABLE 1. Caregiver/child corpus

\begin{tabular}{llcc}
\hline \hline Caregiver's Name & Child's Name & Sex & Child's Age at Time of Recording (years; months) \\
\hline Sheila & Ricky & M & $2 ; 10$ \\
Alice & Max & M & $2 ; 11$ \\
Mary & Isabel & F & $3 ; 0$ \\
Donna & Stephen & M & $3 ; 2$ \\
Paula & Kerry & F & $3 ; 2$ \\
Fran & Lyle & M & $3 ; 3$ \\
Kimberly & Annie & F & $3 ; 3$ \\
Lesley & Lucy & F & $3 ; 4$ \\
Molly & Luke & M & $3 ; 5$ \\
Gail & Ellie & F & $3 ; 5$ \\
Ruth & Kieran & M & $3 ; 6$ \\
\hline \hline
\end{tabular}

overall distribution for caregivers is in line with Guy's (1991b) New York speakers at 33\% and higher than Tagliamonte and Temple's (2005) 24\% for York English. The children's rates of use are very similar to Roberts's (1997:366) child results$37 \%$.

\section{Individual speaker pairs}

In line with Guy (1980), we now consider individual pairs. Figure 1 shows the results. The total number of tokens for each speaker is shown at the top of each bar. A number of observations can be made when the data are viewed in this way. First, in line with Guy's (1980:2) observation that this variable "is rarely categorical," there are no speakers that categorically delete $t / d$ or no speakers who have categorical $t / d$ presence.

Second, when we consider matching between caregiver/child pairs, there is no significant correlation between caregiver and child pairs in the use of $t / d$ deletion $(r=0.131002448, d f=9, p<0.10)$. In other words, no straight matching in terms of rates of use between input and output.

Third, when we examine the rates of deletion by age, the trendline indicates that there is a decrease in the deleted variant as the children get older. Note however, the relatively high rates of deletion by two of the older children, Lucy and Ellie, suggesting that individual differences in rates of use do exist, regardless of age. When we examine caregiver talk and age, the trendline indicates the opposite effect: the older the children, the higher the rates of deletion in caregiver speech. Again, individual differences do exist within this general pattern: Lesley and Gail have relatively high rates of deletion, even though they are caregivers of older children.

Fourth, for gender, the rates of use of $t / d$ are mixed. Looking from left to right along the graph, Ricky, Max, and Stephen have high rates of deletion; Lyle, Luke, and Kieran have relatively lower rates. Isabel, Lucy, and Ellie have high rates of deletion; Kerry and Annie have relatively lower rates. These mixed results are mirrored in the caregiver data: three caregivers of girls (Mary, Paula, and 
TABLE 2. Overall distribution of deletion for caregiver and child data

\begin{tabular}{lccccc}
\hline \hline \multicolumn{3}{c}{ Caregivers } & & & \multicolumn{2}{c}{ Children } \\
\cline { 5 - 6 }$n$ & $\%$ & & & & $\%$ \\
\hline 695 & 29.4 & & 501 & 34.5 \\
\hline \hline
\end{tabular}

$N=1,196$

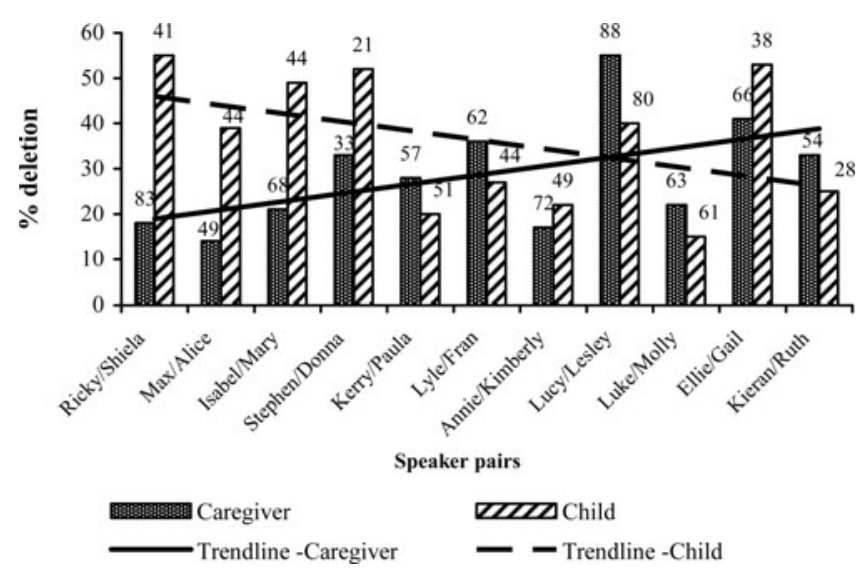

FIGURE 1. Overall distribution of $\mathrm{t} / \mathrm{d}$ deletion by caregiver/child pairs.

Kimberley) have lower rates of deletion than the overall average. Equally, three caregivers of boys (Sheila, Alice, and Molly) also have lower rates.

These initial overall distributions by caregiver/child pairs suggest that (a) there is no simple correlation between input and output in rates of use, and (b) there is a general tendency for rates of deletion to decrease by age in the child speech and increase in the caregiver speech, although individual differences exist. We now turn to a number of other possible constraints and statistical analysis of use.

\section{Individual lexical items}

We first consider individual lexical items. It might be the case that children are merely imitating individual forms modeled by their caregivers instead of acquiring higher level constraints on use evidenced in the adult data (see also Guy \& Boyd, 1990; Roberts, 1997). Our previous research (Smith et al., 2007) has shown that some variables may be copied on a word-for-word basis. To test for this, Table 3 divides the data into frequently occurring lexical items (those which appear more than 25 times in the data: breakfast, find, finished, first, 
TABLE 3. Distribution of t/d deletion in caregiver and child data by lexical item

\begin{tabular}{lrrrr}
\hline \hline & \multicolumn{2}{c}{ Caregivers } & & \multicolumn{2}{c}{ Children } \\
\cline { 2 - 5 } & $n$ & $\%$ & $n$ & $\%$ \\
\hline Breakfast & 9 & 11 & 15 & 40 \\
Find & 29 & 34 & 32 & 53 \\
Finished & 42 & 40 & 59 & 41 \\
First & 39 & 44 & 14 & 21 \\
Found & 15 & 7 & 25 & 20 \\
Hand & 22 & 32 & 18 & 44 \\
Lost & 34 & 15 & 8 & 50 \\
Next & 35 & 43 & 23 & 61 \\
Round & 37 & 19 & 16 & 44 \\
Stand & 28 & 61 & 10 & 50 \\
Want & 15 & 20 & 22 & 41 \\
Other & 390 & 27 & 259 & 27 \\
Total & 695 & & 501 & \\
\hline \hline
\end{tabular}

found, hand, lost, next, round, stand, and want) and those which are less frequent ("other" category), in order to see whether there is a correspondence between caregiver and child rates of deletion across frequent lexical items.

The table shows that aside from the lexical item finished, the rates of use are quite different when the two groups are compared. For example, lost has 15\% deletion in the caregiver data and 50\% deletion in the child data; round has 19\% in the caregiver data and $44 \%$ in the child data. This suggests that the children are not simply imitating individual lexemes with this particular variable.

Neu (1980:53) reported that "high-frequency lexical items are more likely to undergo deletion than are most other items" (see also Bybee, 2000; Jurafsky, Bell, Gregory, \& Raymond, 2001), but Walker (2008) found no such effect. In these data, there is a range of rates of use with the more frequent lexical items (7\%-61\%). Given this, it would be misleading to group the data into frequent versus infrequent, thus we do not consider individual lexical item further.

\section{Multivariate analysis}

We can now proceed to examining the system that may be underlying deletion of / $/$ / or $/ \mathrm{d} /$. We coded for a number of constraints reported in the literature.

Following phonological segment: We follow previous analyses (e.g., Guy, 1980; Neu, 1980; Roberts, 1997; Tagliamonte \& Temple, 2005) in dividing the data into following obstruent, glides, vowels, and pause. In the child data, there were no liquids, and only 12 tokens $(/ \mathrm{r} / n=8, / 1 / n=4)^{6}$ in the adult data, thus these were excluded from the analysis.

Preceding phonological segment: In this analysis, we adopted Guy's (1980) five-way split of the data-sibilant, fricative, nasal, stop, and lateral. With morphological class, we follow Guy's three-way distinction-monomorphemic 
clusters, semiweak verbs, regular past tense verbs. Past participles were also included in this category. ${ }^{7}$

Situational context: In line with Roberts (1997:357), we divide the data into different situational categories although these differ from her categories of book reading, role-playing, picture naming, and other. Our data were divided into play (e.g., playing with toys, hide and seek, make-believe); routine (e.g, getting dressed, going for a walk, tidying up, eating, general talk); teaching (e. g., learning colors, reading books); discipline (e.g., where the child is being rebuked for bad behavior); intimacy (e.g., when the child is being cuddled). In practice, these contexts are not discrete, and in particular, the categories of play and teaching often overlap. In these data, a strict protocol was used in distinguish the different categories. The context was coded as teaching if the caregiver and child were involved in a particular activity to do with for example, colors or names, as in (27). This context was generally characterized by an exaggerated pitch range and question repetition in caregiver speech. The caregiver most often initiated these activities and remained in close, physical proximity with the child for the duration of the task. For play, the caregiver and child might also be involved in some type of activity, such as makebelieve as in (28). However, in these contexts, there was no overt teaching involved through the use of, for example, specific questions. The child often initiated these play interactions, with the caregiver often involved in another activity at the same time. Contexts of discipline were characterized by a raised voice and imperative forms, as in (29). Intimacy included contexts such as (30) and were characterized by frequent terms of endearment. All other contexts were coded as routine. This covered a wide variety of situations from discussing the day's events to what they were going to eat for lunch, as in (31).

(27) Teaching: Fran and Lyle are looking at a book that has the letters of the alphabet

Fran: $\mathrm{O}$ is for-.

Lyle: Oranges.

Fran: Aye. P is for-.

Lyle: Erm panga.

Fran: Panda.

Lyle: Panga.

Fran: $\mathrm{Q}$ is for-.

Lyle: Queen.

(28) Play: Lucy and Lesley playing with Lucy's imaginary friend

Lesley: Fa's (who's) Kika like?

Lucy: Kika go do it on her!

Lesley: Fa's Kika?

Lucy: Kika.

Lesley: Fa's Kika? 
Lucy: Remember my imaginary friend? Go do it on her hand! Go do it on her hand!

Lesley: I canna see her.

Lucy: Look! She's there.

Lesley: Right okay then. Right Kika get your hand out!

(29) Discipline: Fran asks Lyle to come out of the bath

Fran: Right come on then. The water's gone. Out you come before you get cold.

Right come on then! O-U-T out.

(30) Intimacy: Mary and Isabel share a tender moment

Mary: Mammy's baby.

Isabel: I want my mammy. I want my mam. I want my mam.

Mary: I'm here, you silly. Silly billy.

(31) Routine: Ellie and her mother Gail discussing a present for Ellie's baby brother

Ellie: Will we buy a Barbie plate for him?

Gail: $\quad$ Oh I $\varnothing$ na think he'll like Barbie.

Ellie: Nae like Barbie?

Gail: No, boys dinna like Barbie. I think he'll maybe like Bob.

Age: The children are divided into those 3;0 and under and those above 3;0. ${ }^{8}$ The caregivers are divided in the same way. The data are also divided into (caregivers of) boys and (caregivers of) girls.

We now test these social and linguistic constraints simultaneously through Goldvarb X (Sankoff, Tagliamonte, \& Smith, 2005). This will enable us to determine which of the putative factors contribute statistically significant effects to $\mathrm{t} / \mathrm{d}$ deletion when all of them are considered simultaneously. It also allows us to determine the relative magnitude of these effects (shown by the range) in each community and how the hierarchy of constraints operate within these categories. Factor weights above .5 are said to favor $\mathrm{t} / \mathrm{d}$ deletion and below .5 disfavor it.

Table 4 shows the results.

The multivariate analysis shows both similarities and differences between the caregivers and children in terms of significance, hierarchies, and magnitude of effect.

First, all groups are selected as significant for the caregivers; only preceding and following phonological segment and age are selected for the children. In other words, articulatory, grammatical, and stylistic constraints are significant in the caregiver data. Articulatory constraints only, alongside age, are significant in the child data.

The most significant factor group for both caregivers and children is following phonological segment, shown by the highest ranges (47 and 55). This mirrors previous studies where it is found to be the strongest effect. In terms of hierarchies of use, the two groups are very similar: obstruent $>$ glide $>$ pause $>$ vowel, although pause and vowel are barely differentiated in the caregiver data. 
TABLE 4. Variable rule analysis of t/d deletion across caregivers and children

\begin{tabular}{|c|c|c|c|c|c|c|}
\hline & \multicolumn{3}{|c|}{ Caregivers } & \multicolumn{3}{|c|}{ Children } \\
\hline & \multicolumn{3}{|c|}{$\begin{array}{c}\text { (Log likelihood: }-309.737 \\
\text { Input: } 0.242 \text { ) }\end{array}$} & \multicolumn{3}{|c|}{$\begin{array}{c}\text { (Log likelihood: }-261.772 \\
\text { Input: } 0.302)\end{array}$} \\
\hline & FW & $\%$ & $n$ & FW & $\%$ & $n$ \\
\hline \multicolumn{7}{|l|}{ Following phonological segment } \\
\hline Obstruent & .82 & 63 & 150 & .82 & 66 & 116 \\
\hline Glide & .61 & 31 & 84 & .60 & 38 & 29 \\
\hline Pause & .37 & 23 & 240 & .44 & 30 & 208 \\
\hline Vowel & .35 & 13 & 209 & .27 & 13 & 144 \\
\hline Range & 47 & & & 55 & & \\
\hline \multicolumn{7}{|l|}{ Preceding phonological segment } \\
\hline Sibilant & .63 & 42 & 294 & .62 & 42 & 189 \\
\hline Nasal & .45 & 30 & 244 & .54 & 40 & 171 \\
\hline Stop & .32 & 8 & 38 & .33 & 27 & 30 \\
\hline Fricative & .21 & 9 & 56 & .31 & 21 & 29 \\
\hline Lateral & $\mathrm{K} / \mathbf{O}$ & 0 & 63 & .28 & 15 & 81 \\
\hline Range & 42 & & & 34 & & \\
\hline \multicolumn{7}{|l|}{ Morphological class } \\
\hline Monomorpheme & .61 & 37 & 441 & {$[.54]$} & 41 & 288 \\
\hline Past tense & .37 & 18 & 176 & {$[.41]$} & 24 & 166 \\
\hline Semiweak & .21 & 12 & 78 & {$[.57]$} & 34 & 47 \\
\hline Range & 40 & & & & & \\
\hline \multicolumn{7}{|l|}{ Situational context } \\
\hline Play & .57 & 33 & 289 & {$[.52]$} & 37 & 244 \\
\hline Routine & .50 & 29 & 347 & {$[.48]$} & 32 & 232 \\
\hline Teaching/discipline & .22 & 11 & 55 & {$[.52]$} & 33 & 15 \\
\hline Range & 35 & & & & & \\
\hline \multicolumn{7}{|l|}{ Age } \\
\hline (Caregivers of) older children & .56 & 34 & 495 & .44 & 30 & 372 \\
\hline (Caregivers of) younger children & .36 & 18 & 200 & .66 & 47 & 129 \\
\hline Range & 20 & & & 22 & & \\
\hline \multicolumn{7}{|l|}{ Gender } \\
\hline (Caregivers of) girls & .56 & 33 & 351 & {$[.55]$} & 36 & 262 \\
\hline (Caregivers of) boys & .44 & 25 & 344 & {$[.45]$} & 33 & 239 \\
\hline Range & 12 & & & & & \\
\hline Total & & & 695 & & & 501 \\
\hline
\end{tabular}

Note: The factor groups in bold are statistically significant. K/O indicates $0 \%$ deletion.

Previous research has shown that preceding phonological segment is a weak constraint in some dialects (e.g., Guy, 1980; Labov, 1989:90), but strong in others (Bayley, 1994:314; Santa Ana, 1996:68). Here it is a relatively strong effect in both data sets. ${ }^{9}$ Perhaps more importantly, the constraint ranking across the two groups is the same: sibilants $>$ nasals $>$ stops $>$ fricatives $>$ laterals. This differs from Labov's (1989) broad hierarchy /s/ $>$ stops $>$ nasals $>$ other fricatives $>$ liquids, and Tagliamonte and Temple's (2005:288) sibilant $>$ liquid $>$ nasal $>$ stop $>$ nonfricative sibilant. 
One difference with respect to preceding phonological segment is the categorical presence of $\mathrm{t} / \mathrm{d}$ in laterals with the caregivers but variable use in the child data. The results for the caregivers may in part be due to following phonological context: from the 63 contexts of preceding lateral, only 4 are followed by an obstruent, the most favoring context for deletion, and 49 are followed by either pause or a vowel, the least favoring environments. In contrast, in the child data, from the 81 contexts of use, 12 are followed by an obstruent.

For morphological class, note the relatively small number of instances in the semiweak class of verbs. This is a problem that is encountered in many studies of t/d (e.g., Tagliamonte \& Temple, 2005), but it is particularly exacerbated in these data. As mentioned in the section circumscribing the variable context, the Buckie dialect has regularized forms of semiweak verbs (telt for told, selt for sold), thus making the inventory of semiweak verbs even more restricted than normal. Moreover, in the children's speech, there are cases where semiweak verbs are regularized. Setting aside this issue of small number of instances, the multivariate analysis shows that the caregivers and children are very different on this internal constraint. For caregivers, the hierarchy is monomorphemes $>$ regular past tenses $>$ semiweak verbs. On the other hand, this group is not selected as significant for the children, and their constraint hierarchies are at odds with the caregivers: semiweak verbs $>$ monomorphemes $>$ regular past tenses. In other words, semiweak verbs for the children pattern like monomorphemes. ${ }^{10}$

For the different contexts of use, intimacy was removed due to small number of instances (14 total). Teaching and discipline were considered together due to small number of instances and the fact that they patterned in the same way. In the caregiver data, play and routine favor deletion whereas teaching/discipline disfavors it. In the child data in contrast, there is no statistically significant difference between these three contexts of use.

Gender is not statistically significant in the child data but is in the caregivers, with caregivers of girls using higher rates of deletion. This might be explained by one speaker, Lesley. She has the highest rate of deletion at $55 \%$, a full $14 \%$ above the next nearest caregiver. In fact, when we remove this speaker, the result is no longer significant.

Lastly, we examine age. Figure 1 suggested that the younger children use higher rates of deletion than the older children do, and the opposite is true in the caregiver data. This is confirmed in the multivariate analysis. Earlier, we detailed how deletion might better be characterized as absence in some cases. We also discussed how caregiver speech might differ from adult-to-adult speech. Crucial for this analysis is whether the different rates of use reflect different patterns of use. For this reason, we look at the intersection of age and the two significant linguistic constraints in more detail. We first consider following phonological segment, the strongest constraint. Due to small number of instances, we divide the data into two broad categories (see also Roberts, 1997:360-361): obstruent versus pause/vowel for the following phonological segment. We exclude glides as there are too few by individual speaker. Figure 2 shows the results for the caregivers and Figure 3 for the children. 


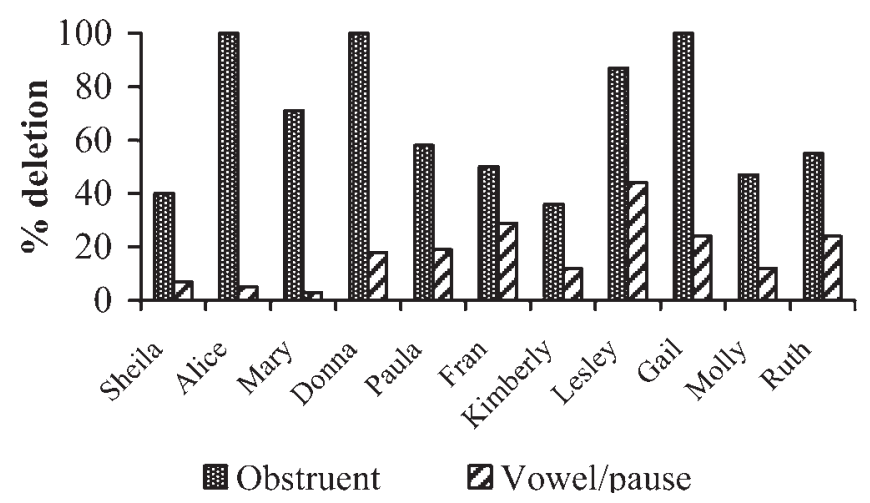

FIGURE 2. Percentage of $\mathrm{t} / \mathrm{d}$ deletion by following phonological segment (caregivers only).

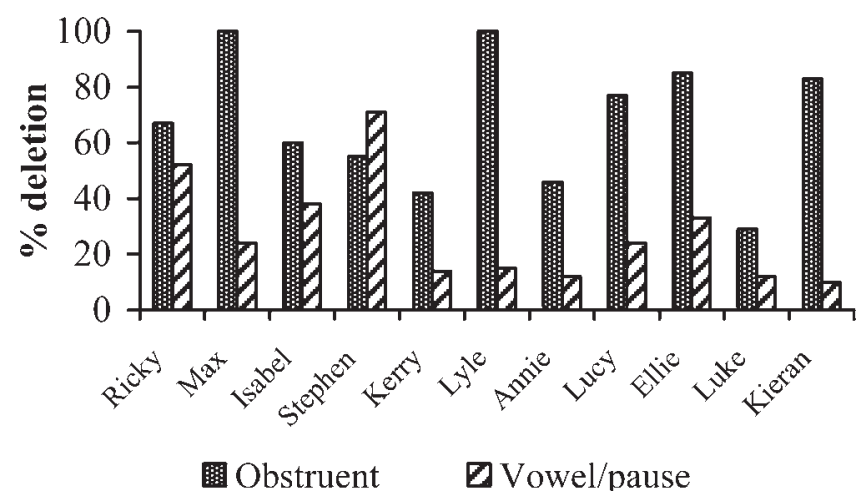

FIGURE 3. Percentage of $\mathrm{t} / \mathrm{d}$ deletion by following phonological segment (children only).

Figure 2 demonstrates that all caregivers have the hierarchy of obstruent $>$ vowel/pause for following phonological segment. With the exception of Stephen, Figure 3 demonstrates that the children also have this hierarchy, including the youngest three speakers.

Figures 4 and 5 show preceding phonological segment by age. In line with the factor weights for the group results, we divide the data into sibilants/nasals versus stops/fricatives/laterals.

Figure 4 shows that all caregivers have higher rates of use across sibilants and nasals. In fact, with 6 speakers, there is categorical t/d presence in stops, fricatives, and laterals. For the children, Figure 5 shows the more-to-less hierarchy of sibilant/nasal $>$ stops/fricatives/nasals across in 9 of the 11 speakers. Only Isabel, a younger speaker, and Ellie, an older one, do not demonstrate this hierarchy. However, the difference in use between the 2 groups of segments is not so stark in the child data, probably due to the fact that they do not have the categorical presence of $\mathrm{t} / \mathrm{d}$ with preceding laterals. 


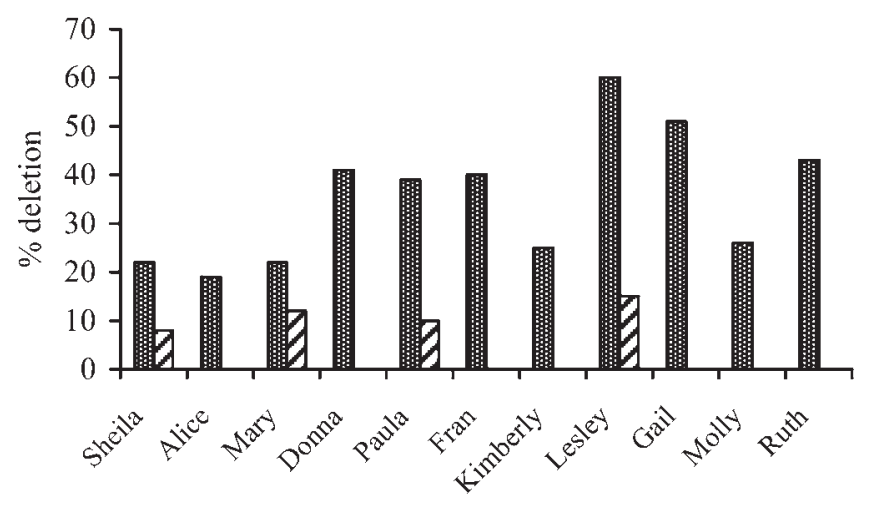

四 Sibiliants/nasals D Stops/fricatives/laterals

FIGURE 4. Percentage of $\mathrm{t} / \mathrm{d}$ deletion by preceding phonological segment (caregivers only).

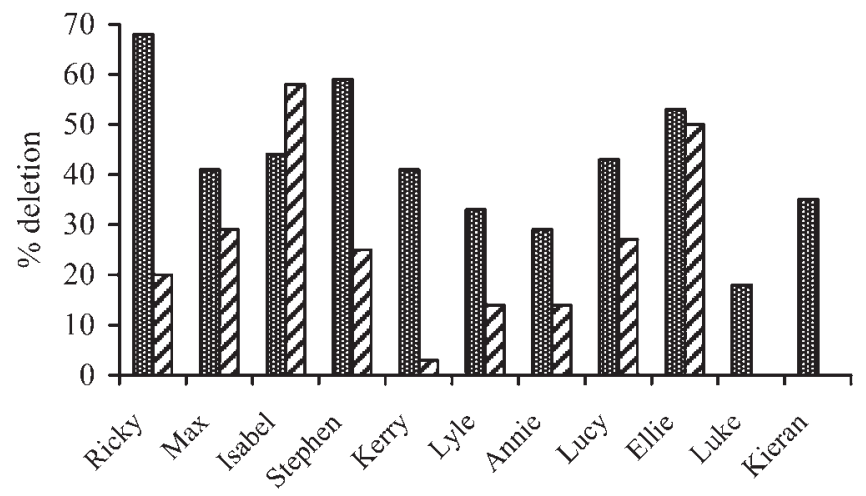

䎳 Sibiliants/nasals $\square$ Stops/fricatives/laterals

FIGURE 5. Percentage of $\mathrm{t} / \mathrm{d}$ deletion by preceding phonological segment (children only).

This more detailed analysis shows that the group constraints are on the whole replicated by the individuals.

In sum, the distributional and multivariate analysis reveals that:

All caregivers and all children have variable use of $\mathrm{t} / \mathrm{d}$ deletion.

The overall frequencies of use reflect those reported for other dialects.

There is no statistically significant matching between caregiver and child pairs in term of overall frequencies of use.

There is a general tendency for rates of deletion to decrease as the children get older, and for deletions remove $-\mathrm{s}$ to decrease in the caregiver data as the children gets older. However, individual differences exist. 
For caregivers, all groups are selected as significant to t/d deletion. For children, articulatory constraints and age are significant.

For preceding and following phonological segments remove $-\mathrm{s}$, children largely mirror the hierarchies of use evidenced in their caregiver speech whether these are universal or dialect-specific. The group patterns are replicated across the individual speakers.

For morphological class, the children do not have the same patterns of use as their caregivers.

Caregivers show style-shifting in the different situational contexts of use. Children do not.

Gender is not significant for the children or for the caregivers when the outlying speaker (Lesley) is removed.

\section{Comparison with Roberts's findings}

How do these results compare with Roberts's Philadelphian children? On two points we can compare directly: following phonological segment and morphological class. Figure 6 shows the factor weights for following phonological class across the caregivers and children in Buckie and Philadelphia.

Figure 6 shows that the similarities across all four groups are striking. For all groups, the factor weights for obstruents and glides are higher than for pause and vowel. In fact, the only slight difference is the higher rates of deletion for vowel in the Philadelphian children's data. When Roberts (1997:361) divided her data by individual speakers, the patterns of use of more to less held, just as in our data.

We can also compare directly the findings for morphological class. Figure 7 shows the results.

Again, the comparison is striking. With this measure, however, the split is between caregivers in Philadelphia and Buckie, on the one hand, and children in Philadelphia and Buckie, on the other: semiweak and regular past tense verbs

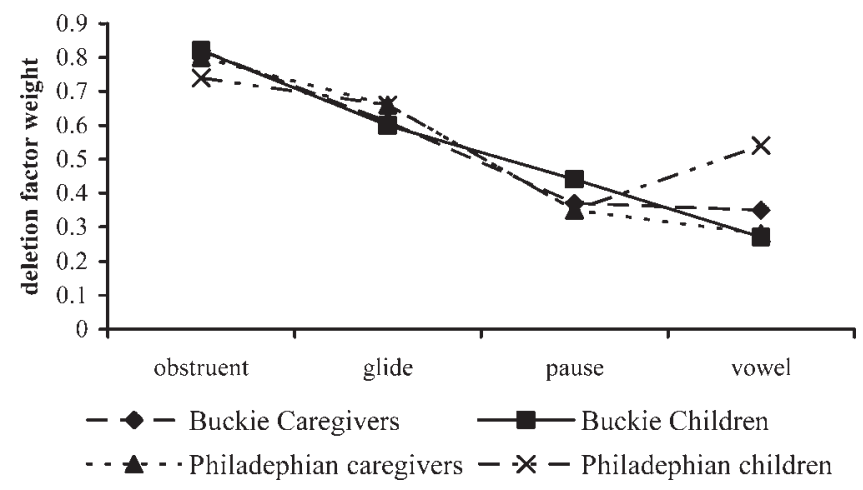

FIGURE 6. Comparison of factor weights for following phonological segment of Buckie and Philadelphia caregivers and children. 


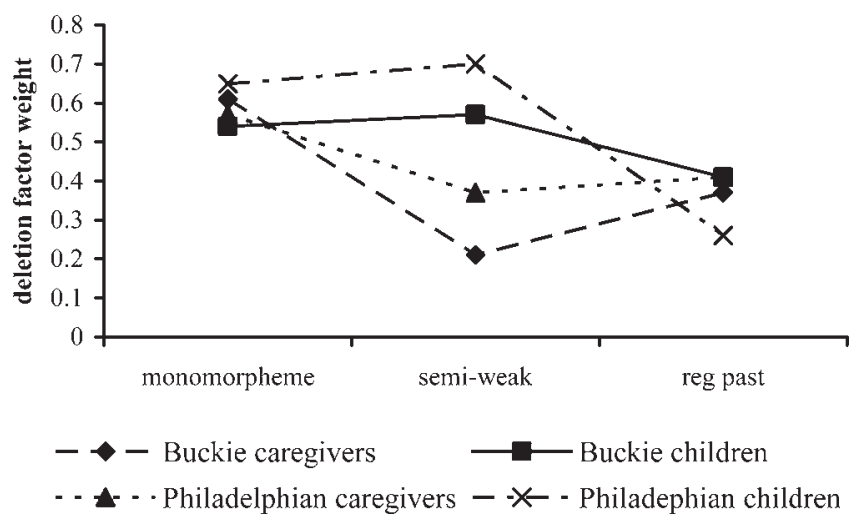

FIGURE 7. Comparison of factor weights for morphological class of Buckie and Philadelphia caregivers and children.

disfavor deletion in the caregiver data across both communities; semiweak verbs pattern like monomorphemes in the child data across both communities. With individual speaker use, the hierarchy of monomorphemes $>$ regular past tense held in Roberts's data, as it did ours.

\section{I S C U S S I O N}

In this study, we set out to examine the acquisition of a well-documented linguistic variable: $\mathrm{t} / \mathrm{d}$ deletion. Specifically, we sought to discover whether results of previous analyses (Roberts, 1995, 1997) would be replicated in a completely different variety and to explore more directly the impact of caregiver input on acquisition of this feature. What have we found?

\section{Overall rates of use}

We began by examining overall rates of use across caregiver and child talk. The distributional analysis demonstrated that the rates of use in both groups were similar to those of previous studies. Moreover, they were also similar to each other: there was no statistically significant difference in frequencies between the two groups. However, when we divided the data into caregiver/child pairs (Figure 1), we found no statistically significant matching between caregiver/ child pairs, in other words, there is no simple correlation between rates of input and output in these data. This encouraged us to explore more fully the patterns of $\mathrm{t} / \mathrm{d}$ deletion within and between the two groups. What did we find?

\section{Individual lexical items}

We first dealt with the possibility that children may be learning the rules of $t / d$ deletion on a word-by-word basis, especially in cases where the lexical item is 
very frequent. There is certainly an aspect of lexical restriction on the use of $\mathrm{t} / \mathrm{d}$ beyond the usual items such as and and just in this dialect, and this "lexicalized reduction" is also noted in other varieties (e.g., Torbert, 2001:375). We documented the use of some lexical items that were (near) categorical in the caregiver data. They were also (near) categorical in the child data. These particular items, identified in the history of Scots, may well have been learned on a word-by-word basis. However, when we looked at the very frequent lexical items that varied in their realizations, very few of these showed similar frequencies between the caregivers and children, suggesting that there were systems other than mere word-by-word imitation underlying $\mathrm{t} / \mathrm{d}$ deletion. The constraints on use would allow us to reveal what these were.

\section{Caregivers}

Although there was no statistically significant matching between caregivers and children in terms of overall rates of deletion, the frequencies across individual caregivers revealed that there was a general tendency for rates of deletion in the caregiver speech to increase as the children got older. This was demonstrated by the trendlines in Figure 1 and shown to be statistically significant in the multivariate analysis. We have already discussed how caregiver talk might differ from adult-to-adult talk in terms of "clearer articulation." Further, Foulkes, Docherty, and Watt (2005:201) found that caregiver talk "gradually becomes more similar in character to that of interadult mode as the children get older," and our previous research has also shown that some variables pattern in this way (Smith et al., 2007). Extrapolating from these findings, we might expect that clearer articulation of consonant clusters would result in fewer deleted variants, especially with younger speakers. Thus elements of "caregiverese" might best explain this increase in the deleted variant in caregiver speech as the children get older. If this were the case, might different rates of use impact on different patterns of use?

The multivariate analysis revealed that all groups, both social and linguistic, were selected as significant to $\mathrm{t} / \mathrm{d}$ deletion in caregiver speech. Further, their patterns of use largely reflected those that have been attested for other dialects. In terms of the linguistic constraints, following phonological segment exerted the strongest effect on deletion of $t / d$ and the constraint ranking within this group was very similar to previous studies. The results for morphological class differ from a number of previous studies where semiweak verbs are usually situated between monomorphemes and regular past tenses. However, it is not unusual for semiweak verbs to pattern inconsistently in adult data (e.g., Guy, 1977, 1980), or at least have no significant difference, no doubt in part due to the small number of instances in this category. Thus, the claim to universality generally holds in the caregiver speech across these two major constraints. Preceding phonological segment is also significant. Here dialect-specific ordering of nasals is noted and perhaps more importantly, these override the sonority 
hierarchy detailed previously: nasals favor deletion more than stops and fricatives. This hierarchy of use may be explained in the history of Scots, where preceding $/ \mathrm{n} /$ is said to favor deletion. We suggest that these data may reflect a continuation of these dialect-specific patterns over many centuries and these can outweigh the more universal, articulatory restrictions attested in other dialects.

When we examined these linguistic constraints by individual speakers, the group patterns were largely replicated. These group and individual results lead us to conclude that caregiverese may have an impact on rates of use, but not on patterns of use.

In terms of the social constraints, age, gender, and situational context were all significant, but with the proviso of possible data skewing with gender. Labov (2001:196) remarked that this variable "elicit[s] only moderate style shifting" but in these data, the slope of style-shifting between the different contexts is fairly pronounced: compare, for example, .54 and .52 for play and routine, respectively, with .24 for teaching. We have already suggested that age differences might be explained by some element of caregiverese. We suggest the same explanation for style-shifting, where "talking clearly" is particularly prevalent in those contexts where the caregiver may be monitoring her speech more carefully, hence lower rates of the deleted variant. Moreover, this talking clearly may transcend gender distinctions with this variable. Foulkes et al. (2005:189) demonstrated that mothers of girls show lower rates of the stigmatized variant when compared with mothers of boys, suggesting some type of evaluation of variant form. Once the outlying speaker has been removed, the results suggest that there is no such evaluation of $t / d$ deletion takes place in this community with respect to gender. We interpret this as caregivers giving their child the "best linguistic start" in life through the careful articulation of forms in particular circumstances, regardless of whether their child is a boy or a girl.

\section{Children}

In contrast to the caregiver data, Figure 1 demonstrated that there was a decrease in rates of deletion as the children get older. This could be a result of developmental processes: as detailed earlier, consonant cluster reduction is a well-attested phenomenon in child speech, arising from the relatively late development of past tense -ed marking and more general articulatory limitations found in the earlier years. For younger speakers, t/d deletion might better be characterized as $\mathrm{t} / \mathrm{d}$ absence, where incomplete acquisition of clusters in early childhood is gradually replaced by systematic deletion of underlying clusters of the type we see in adult data. In these circumstances, $\mathrm{t} / \mathrm{d}$ absence would be predicted to pattern very differently from $\mathrm{t} / \mathrm{d}$ deletion. However, the subsequent analysis indicated this is not the case as we now discuss more fully.

The multivariate analysis of the child data revealed that there are both similarities and differences when compared with the caregiver data. First, only three factor groups were selected as significant to t/d deletion: (a) preceding and (b) following phonological segment and (c) age. The constraints for following phonological segment matched those of the caregivers and hence the widely 
attested universal constraints. In addition, the dialect-specific findings for preceding phonological segment in the caregiver data, where nasals have higher rates of deletion than stops, fricatives, and laterals, are matched by the children. This suggests that these historically attested patterns are passed on from one generation to the next. Perhaps more importantly, it provides evidence of the role of input alongside more universal, articulatory constraints such as the sonority hierarchy in the acquisition of this form. In contrast to these articulatory similarities, morphological class was not significant in the child data; moreover, the constraint hierarchies within this factor group differed from the caregivers. Semiweak verbs patterned with monomorphemes, lending support to the claim that children treat this class of verbs as noninflectional in the earlier years, and only later as bimorphemic (e.g., Guy, 1980).

The further analyses of linguistic constraints across individual speakers demonstrated that even the youngest speakers who had been shown to have higher rates of deletion overall replicated the group patterns. The results for preceding and following phonological segment by individual speakers lead us to conclude that the active period for the acquisition of $t / d$ (Labov, 1989) is earlier than 4 years old. As we have shown, even our youngest speakers-below 3 years old - are well on the way to acquisition of this form. We suggest that we may need to have data from even younger children if we wish to view the gradual replacement of $\mathrm{t} / \mathrm{d}$ absence with $\mathrm{t} / \mathrm{d}$ deletion.

With gender, there was no statistically significant difference in use between boys and girls. This might not be surprising, given the findings for caregiver data and for adult data more generally where gender differences are found to be a relatively weak constraint (e.g., Santa Ana, 1992).

Lastly, situational context was also not significant, despite it being fairly style stratified in the caregiver speech. It might be hypothesized that these children are simply too young to acquire stylistic switching. Although this might be the case with this variable, it is not the case with all variables: in our previous and ongoing work (Smith et al., 2007; Smith, Durham, Fortune, \& Steele, forthcoming), we find that some variables show extreme style-shifting in children's speech and the patterns of use replicate those of the caregivers. Labov (1997) stated that in the transmission of $t / d$ deletion, "it is possible that the frequency of deletion is maintained by the frequency of perception in the process of probability matching." Although we assume some level of perception of the competing variants - this is demonstrated in the dialect-specific effect of preceding nasal-this is not strong enough to effect stylistic shifting with this variable in these early years. In fact, the closest probability matching arises from articulatory constraints thus perception may only be partly implicated in the observed variation.

\section{Similarities across dialects}

When we compared our findings with Roberts's $(1995,1997)$, the similarities are clear. A direct comparison of following phonological segment revealed the same hierarchies of use, as did morphological class, where young speakers have the 
same rates of deletion in semiweak verbs as they do in monomorphemes. This lends further support to the argument that this constraint is subject to age-grading (Guy \& Boyd, 1990). In terms of social constraints, in line with the findings for the Buckie children, Roberts's children too had not acquired the stylistic or gender differences that are attested in adult data. We conclude from these results that two groups of children, separated geographically, culturally, and sociohistorically, acquire this variable at the same time and in the same way.

\section{Order of acquisition}

We are now in a position to reassess Labov's (1989:96) observation on this variable, specifically, if $\mathrm{t} / \mathrm{d}$ deletion "were controlled by innate, universal principles, then we would expect to find the following order of acquisition": articulatory constraints, grammatical constraints, and replace 'and' with 'then' stylistic and social constraints. Our results, in tandem with Roberts's findings, strongly support this prediction. This analysis has revealed that the children in Buckie have acquired the articulatory constraints in use, both as a group and as individuals. In contrast, they are only partway to acquiring the morphological constraints but do not at this stage indicate patterns of style-shifting. This suggests that universal, dialect-specific, social, and higher level abstract rules enter into the grammar of the child incrementally: the more mechanical aspects of this variable come first, followed by the higher level rules of use, and finally the social constraints.

\section{CONCLUSIONS}

We have documented the use of $t / d$ deletion in caregiver/child interaction in a Scottish dialect. The analysis shows that the widely attested constraints on use are replicated not only in caregiver speech but also in child speech from the very earliest stages. Moreover, these constraints are learned in tandem with more general acquisition processes. This contributes to the growing body of evidence that shows that variable rules are acquired at the same time as categorical rules (e.g., Foulkes et al., 1999, 2005; Roberts \& Labov, 1995) and highlights how "the complexities of variation well-documented in adult language have their beginnings much earlier” (Roberts, 1997:369).

\section{NOTES}

1. Within the hierarchy of following segment, Guy (1991a) found that /l/ and /r/ behaved differently. He suggested that the effect of the constraint is largely due to whether or not the consonant in question can resyllabify onto the following onset, as in (a), or where resyllabification is blocked by the nonacceptability of such clusters, as in (b) (but see Labov, 1997; Tagliamonte \& Temple, 2005):

a) just read $=(/$ tr- $/)$. (caregiver)

b) just leave $=(* / \mathrm{tl}-/)$. (caregiver)

2. Guy (1991a) suggested something different: in a lexical phonology framework, a t/d deletion rule applies first to roots, then to stems, then to words, with the retention rates related exponentially. Thus the observed quantitative patterns of use and identical hierarchies across a diverse range of dialects. 
3. Though these constraints are reported in the main for North American varieties, Tagliamonte and Temple's (2005:299) study of the dialect of York, England, found no statistically significant effect of morphological class, leading them to conclude that there may be "differences of consequence" between North American and British varieties with this constraint. Patrick $(1991,1999)$ also found the results for Jamaican Creole at odds with other studies. He attributed this to the fact that, for every speaker in his sample, Jamaican Creole consistently shows variable past tense marking forms.

4. See Davis and Lindblom (2001) for an alternative view.

5. Also noted for the history of Scots is $t / d$ deletion after the stops $/ \mathrm{p} /$ and $/ \mathrm{k} /$; However, we found robust variability in this context, hence these contexts were not excluded.

6. Due to small number of instances, Guy's (1980) resyllabification hypothesis cannot be tested on these data.

7. Labov and Cohen (1967) and Wolfram (1969) considered only a two-way distinction, but Tagliamonte and Temple (2005) operated a four-way distinction, separating past participles from regular past tense verbs.

8. This division may be somewhat arbitrary. However, in this sample, this represents the only break in age terms (i.e., between 3;0 and 3;2).

9. In fact, given the knockout for laterals in the caregiver data, it could be argued to be the strongest effect.

10. It should be noted that there very few semiweak verb types used across both groups: left, lost, found, told, kept, meant, felt, slept, and built appear in the data.

\section{REFERENCES}

Bayley, Robert. (1994). Consonant cluster reduction in Tejano English. Language Variation and Change 6:303-326.

Brown, Roger. (1973). A first language. Cambridge, MA: Harvard University Press.

Bybee, Joan. (2000). The phonology of the lexicon: Evidence from lexical diffusion. In M. Barlow \& S. Kemmer (eds.), Usage-based models of language. Stanford, CA: CSLI Publications.

Chambers, Jack K. (2003). Sociolinguistic theory. Oxford: Blackwell Publishers Ltd.

Davis, Barbara, \& Lindblom, Austin. (2001). Phonetic variability in baby talk and development of vowel categories. In F. L. Claes von Hofsten \& M. Heimann (eds.) Emerging cognitive abilities in early infancy. Hahwah, NJ: Lawrence Erlbaum. 135-171.

Dictionary of Scots Language. (2008). Available at: http://www.dsl.ac.uk/dsl/. Accessed: July 29, 2008.

Fasold, Ralph. (1972). Tense marking in Black English: A linguistic and social analysis. Arlington, VA: Center for Applied Linguistics.

Foulkes, Paul, Docherty, Gerry, \& Watt, Dom. (1999). Tracking the emergence of structured variation: Realisations of (t) by Newcastle children. LeedsWorking Papers in Linguistics and Phonetics 7:1-25. (2005). Phonological variation in child-directed speech. Language 81(1):177-206.

Garnica, Olga. (1977). Some prosodic and paralinguistic features of speech to young children. In C. E. Snow \& C. A. Ferguson, (eds.) Talking to children: Language input and acquisition. Cambridge: Cambridge University Press. 63-88.

Guy, Gregory. (1977). A new look at -t, -d deletion. In R. W. Fasold \& R. W. Shuy, (eds.) Studies in language variation. Washington, DC: Georgetown University Press. 1-11.

(1980). Variation in the group and the individual: The case of final stop deletion. In W. Labov (ed.), Locating language in time and space. New York: Academic Press. 1-36.

(1991a). Explanation in variable phonology: An exponential model of morphological constraints. Language Variation and Change 3(1):1-22.

(1991b). Contextual conditioning in variable lexical phonology. Language Variation and Change 3(2):223-239.

Guy, Gregory, \& Boberg, Charles. (1997). Inherent variability and the obligatory contour principle. Language Variation and Change 9:149-164.

Guy, Gregory, \& Boyd, Sally. (1990). The development of a morphological class. Language Variation and Change 2:1-18.

Jurafsky, Dan, Bell, Allan, Gregory, Michelle, \& Raymond, William. (2001). Probabilistic relations between words: Evidence from reduction in lexical production. In J. Bybee \& P. Hopper (eds.), Frequency and the emergence of linguistic structure. Amsterdam: John Benjamins. 229-254.

Kiparsky, Paul. (1982). Lexical phonology and morphology. In I.-S. Yang (ed.), Linguistics in the morning calm. Seoul: Hanshin. 3-91. 
Kirk, Cecilia, \& Demuth, Katherine. (2005). Asymmetries in the acquisition of word-initial and wordfinal consonant clusters. Journal of Child Language 32 (4):709-734.

Labov, William. (1975). Language in the inner city. Philadelphia: University of Pennsylvania Press. (1989). The child as linguistic historian. Language Variation and Change 1:85-97.

(1997). Resyllabification. In F. Hinskins, R. van Hout \& L. Wetzels (eds.), Variation, change and phonological theory. Amsterdam: John Benjamins. 145-179.

(2001). Principles of linguistic change: Social factors. Oxford: Blackwell Publishers.

Labov, William, \& Cohen, Paul. (1967). Systematic relations of standard and non-standard rules in the grammars of Negro speakers. Project Literacy Reports No. 8. Ithaca, NY: Cornell University. 66-84.

MacWhinney, Brian. (1991). The CHILDES project: Tools for analyzing talk. Hillsdale, NJ: Lawrence Erlbaum Associates.

Malsheen, Bathsheba. (1980). Two hypotheses for phonetic clarification in the speech of mothers to children. In G. Yeni-Komshian, J. Kavanagh \& C. Ferguson (eds.), Child phonology. Vol. 2. Perception. New York: Academic Press. 173-184.

McLeod, Sharynne, van Doorn, Jan, \& Reed, Vicki. (2001a). Normal acquisition of consonant clusters. American Journal of Speech-Language Pathology 10:99-110.

(2001b). Consonant cluster development in two-year-olds: General trends and individual difference. Journal of Speech, Language, Hearing Research 44:1144-1171.

Neu, Helene. (1980). Ranking of constraints on /t,d/ deletion in American English: A statistical analysis. In W. Labov (ed.) Locating language in time and space. New York: Academic Press. 37-54

Patrick, Peter. (1991). Creoles at the intersection of variable processes: - $t, d$ deletion and past-tense marking in the Jamaican mesolect. Language Variation and Change 3:171-189.

(1999). Urban Jamaican Creole: Variation in the mesolect. Varieties of English Around the World G17. Philadelphia: John Benjamins.

Radford, Andrew. (1992). The acquisition of the morphosyntax of finite verbs in English. In J. M. Meisel, (ed.), The acquisition of verb placement: Functional categories and V2 phenomena in language acquisition. Kluwer: Dordrecht. 23-62.

Reynolds, William. (1994). Variation and phonological theory. Ph.D. dissertation, University of Pennsylvania.

Roberts, Julie. (1995). The acquisition of variable rules: $t$,d deletion and -ing production in preschool children. Ph.D. dissertation, University of Pennsylvania.

(1997). Acquisition of variable rules: a study of (-t,d) deletion in preschool children. Journal of Child Language 24:351-372.

(2002). Child language variation. In J. K. Chambers, P. Trudgill \& N. Schilling-Estes (eds.), Handbook of language variation and change. Oxford: Blackwell. 333-348.

Roberts, Julie, \& Labov, William. (1995). Learning to talk Philadelphian. Language Variation and Change 7:101-122.

Sankoff, David, Tagliamonte, Sali, \& Smith, Eric. (2005). Goldvarb X: A variable rule application for Macintosh and Windows. Department of Linguistics, University of Toronto.

Santa Ana, Otto. (1992). Chicano English evidence for the exponential hypothesis: A variable rule pervades lexical phonology. Language Variation and Change 4:275-288. 8:63-89.

(1996). Sonority and syllable structure in Chicano English. Language Variation and Change

Shriberg, Lawrence, \& Kwiatkowski, Joan. (1980). Natural process analysis. New York: John Wiley.

Smith, Jennifer. (2000a). Synchrony and diachrony in the evolution of English: Evidence from Scotland. D.Phil. dissertation, University of York.

(2000b). You Ø na hear o' that kind o’ things: Negative do in Buckie Scots. English World-Wide 21(2):231-259.

(2001). Negative concord in the Old and New World: Evidence from Scotland. Language Variation and Change 13(2):109-134.

Smith, Jennifer, Durham, Mercedes, \& Fortune, Liane. (2007). "Mam, ma troosers is fa' in doon!": Community, caregiver and child in the acquisition of variation in a Scottish dialect. Language Variation and Change 19(1):63-99.

Smith, Jennifer, Durham, Mercedes, Fortune, Liane, \& Steele, Hazel. (forthcoming). The acquisition of markers, indicators and stereotypes in pre-school children.

Snow, Catherine. (1995). Issues in the study of input: Finetuning, universality, individual and developmental differences, and necessary causes. In P. Fletcher \& B. MacWhinney (eds.), The handbook of child language. Oxford: Blackwell. 180-193. 
Stoel-Gammon, Carol. (1987). Phonological skills of 2-year-olds. Language, Speech, and Hearing Services in Schools 18:323-329.

Stuart-Smith, Jane. (2003). The phonology of modern urban Scots. In J. Corbett, J. D. McClure \& J. Stuart-Smith (eds.), The Edinburgh companion to Scots. Edinburgh: Edinburgh University Press. 110-137.

Tagliamonte, Sali, \& Temple, Rosalind. (2005). New perspectives on an ol' variable: (t,d) in British English. Language Variation and Change 17:281-302.

Torbert, Benjamin. (2001). Tracing Native American language history through consonant cluster reduction: The case of Lumbee English. American Speech 76: 361-387.

Walker, James. (2008). On the role of frequency and the lexicon in phonological variation: (t/d)-deletion in Toronto English. Presented at Canadian Linguistic Association, University of British Columbia.

Waring, Robert, Fisher, John, \& Atkin, Neil. (2001). The articulation survey: Putting numbers to it. In L. Wilson \& S. Hewat (eds.), Proceedings of the 2001 Speech Pathology Australia national conference: Evidence and innovation. Melbourne: Speech Pathology Australia. 145-151.

Wolfram, Walt. (1969). A sociolinguistics description of Detroit Negro speech. Washington, DC: Center for Applied Linguistics.

Wolfram, Walt, \& Christian, Donna. (1976). Appalachian speech. Arlington, VA: Center for Applied Linguistics. 